\title{
The supply side to procurement in a health market: competition and innovation in hip implants
}

\author{
Charlotte Davies \\ Norwich Medical School \& Centre for Competition Policy
}

CCP Working Paper 20-1

\begin{abstract}
Most research on procurement of medical devices focuses on buyer behaviour e.g. in the UK, purchasing strategies by the NHS. This paper is a rare case study of the other side of the market. We investigate competition in the artificial hip implant market in England and Wales, using National Joint Registry data for 2005-18. The analysis is in three parts. We first proceed as would a competition agency, by assessing the nature and structure of the market. We find a highly concentrated duopolistic market structure, in which there has been no significant entry or exit, except a merger between the much smaller 3rd and 4th largest suppliers. Viewed through the eyes of a competition economist, such a structure might be indicative of weak competition. However, concentration is not necessarily synonymous with low competition: it might be that technology dictates that only a small number of firms can survive profitably in the market, but that there is still the cut and thrust of competition leading to forever changing identities of the leading firms. In the second part of the paper, we address these possibilities in two ways, using a novel exploration of market share dynamics and an international comparison. On dynamics, we find an important difference between the two sectors of the market: in traditional cemented prostheses, there is little evidence of any share mobility amongst firms. Indeed, the only discernible change is that Stryker, already the dominant firm, has steadily further increased its market share over time. On the other hand, the uncemented sector has exhibited much more share mobility. Interpreting the uncemented sector as a comparator, this suggests the need for further investigation of the cemented sector. This conclusion is also indirectly reinforced by an international comparison of market structure, from which the most striking feature is the much larger market share of Stryker than in any other European country. In the third part of the paper, we explore the performance of the firms concerned, using innovation as the measure. We find only limited evidence of the emergence of new brands of implants - the smaller suppliers have had little success in introducing new brands and the two main suppliers appear to have concentrated on updating their existing brands. There is also little evidence of competition from generic brands, (in contrast to the picture in many parts of the pharmaceutical sector). Looking to the future, our findings are not necessarily conclusive evidence of a weakly performing, anti-competitive market, but they are sufficient to justify further more micro-survey research to identify the preferences and practices of the main players: surgeons, hospital procurement and the suppliers themselves. The need for such research is heightened by the fact that contemporary policy advice increasingly advocates that cemented prostheses should be preferred, especially for older patients.
\end{abstract}

Contact Details: Charlotte Davies 


\title{
The supply side to procurement in a health market: competition and innovation in hip implants
}

\author{
Dr Charlotte Davies, Senior Research Associate \\ Norwich Medical School, University of East Anglia
}

\section{Abstract}

Most research on procurement of medical devices focuses on buyer behaviour e.g. in the UK, purchasing strategies by the NHS. This paper is a rare case study of the other side of the market. We investigate competition in the artificial hip implant market in England and Wales, using National Joint Registry data for 2005-18. The analysis is in three parts. We first proceed as would a competition agency, by assessing the nature and structure of the market. We find a highly concentrated duopolistic market structure, in which there has been no significant entry or exit, except a merger between the much smaller $3^{\text {rd }}$ and $4^{\text {th }}$ largest suppliers. Viewed through the eyes of a competition economist, such a structure might be indicative of weak competition. However, concentration is not necessarily synonymous with low competition: it might be that technology dictates that only a small number of firms can survive profitably in the market, but that there is still the cut and thrust of competition leading to forever changing identities of the leading firms. In the second part of the paper, we address these possibilities in two ways, using a novel exploration of market share dynamics and an international comparison. On dynamics, we find an important difference between the two sectors of the market: in traditional cemented prostheses, there is little evidence of any share mobility amongst firms. Indeed, the only discernible change is that Stryker, already the dominant firm, has steadily further increased its market share over time. On the other hand, the uncemented sector has exhibited much more share mobility. Interpreting the uncemented sector as a comparator, this suggests the need for further investigation of the cemented sector. This conclusion is also indirectly reinforced by an international comparison of market structure, from which the most striking feature is the much larger market share of Stryker than in any other European country. In the third part of the paper, we explore the performance of the firms concerned, using innovation as the measure. We find only limited evidence of the emergence of new brands of implants - the smaller suppliers have had little success in introducing new brands and the two main suppliers appear to have concentrated on updating their existing brands. There is also little evidence of competition from generic brands, (in contrast to the picture in many parts of the pharmaceutical sector). Looking to the future, our findings are not necessarily conclusive evidence of a weakly performing, anti-competitive market, but they are sufficient to justify further more micro-survey research to identify the preferences and practices of the main players: surgeons, hospital procurement and the suppliers themselves. The need for such research is heightened by the fact that contemporary policy advice increasingly advocates that cemented prostheses should be preferred, especially for older patients. 


\section{Introduction}

NHS procurement continues to be a highly topical subject, attracting a great deal of recent policy focus[1-5]. The NHS is a near monopsony with significant buyer power, but literature has shown that purchasing has tended to take place at a more micro level, i.e. at the individual hospital, and this may have constrained the ability of the NHS to exploit its potentially dominant buying share. The NICE guidance of 2014[6] on THR, noted that there is considerable uncertainty surrounding the prices of prostheses. This was rapidly followed by the pivotal report by Lord Carter of Coles in 2016[5] which highlighted unwarranted variations in prices paid across resource areas, estimating that, by removing these, efficiency savings would be approximately $f 5 \mathrm{bn}$. Another, more clinically specific, policy development was the 'Getting it Right First Time (GIRFT)' initiative led by Professor Tim Briggs[3]. The GIRFT pilot project focussed on Orthopaedics, more specifically hip replacement, suggesting that (amongst other things) hospitals should specialise on implanting only a small number of brands and use cemented rather uncemented implants for patients aged 68 years plus (which has since been supported by a further studies[7-9]). If all their recommendations were adopted, they estimated this would generate a saving of $£ 2$ billion to the NHS over the next 5 years. GIRFT has now been rolled out nationally and is focussing on a further 30 medical specialties.

Although the academic and policy literatures on NHS procurement are extensive, there has been very little research or policy that has focussed on the supply side of procurement. In the case of total hip replacement (THR) surgery, this is the suppliers of the hip implants. Little is known about competition between these firms, and how they interact with the NHS, yet their behaviour is equally important if efficient (for the consumer) market outcomes are to be secured. If competition pressures are sufficiently strong, this will compel suppliers to offer high quality and low price. But, on the contrary, if they have market seller power, this might offset the potential buyer power of the NHS.

\subsection{An antitrust perspective}

This paper attempts to fill this gap in the literature, by investigating the nature of competition between suppliers in the artificial hip implant market in England and Wales, using National Joint Registry (NJR) data for 2005-16. Bearing in mind that we will focus on competition issues which are generic to all markets, we frame our analysis along the lines that would be used by a competition authority (CA) or antitrust agency when tasked with assessing the nature of competition in a given market (perhaps for 
one of its merger or market study investigations ${ }^{1}$ ). In academic terms, many of the basics of competition law derive from the study of Industrial Organisation (IO) and Competition Economics - a field of economics which focusses on understanding the behaviour of firms and their impact on consumers in terms of the structure of the markets and industries in which they compete. One of the key objectives of $\mathrm{IO}$ is to define market power, the ability of suppliers to set prices above the marginal cost. Where market power exists it can lead to any or all of the following: lower quality, restricted choice, slow innovation, barriers to entry as well as higher prices. In policy terms, the CMA[10] defines 'Competition (as) the process of rivalry over time between businesses seeking to win customers' business by offering them a better deal'.

The typical approach adopted by CAs [11] when conducting their assessments is to first define the market in an economically meaningful way so as to include all competing firms appropriately. We do this in section 2, in which we identify two broad sectors of the market - cemented and uncemented prostheses. With the market defined, the CA then assesses various aspects of market structure, notably concentration as measure of the degree of oligopoly. We do this in section 3 . The assessment will also consider various dynamic features of the market, including how much new entry and exit occurs and whether concentration is persistently high. In section 4 we do this using a novel approach which focuses on the churn in market shares of individual firms. We argue that this is a better indicator of the ebb and flow of competition than static levels of concentration. It also provides an interesting comparison between cemented and uncemented. In section 5, we introduce an alternative comparison, this time international, we compare market structure in England and Wales with those in other major European countries. In the third stage, the CA goes on to assess the impact of that structure on various aspects of market performance. In general terms, performance can be measured in various ways including profits, price, quantity, quality, and productivity. Here, in the absence of price data, we focus on innovation, which currently offers the best opportunity, in terms of data available in the NJR. We do this in section 6, with data on innovation at the disaggregated implant brand level. In section 7, we summarise and argue for future research of the main actors (surgeons, hospitals and suppliers), based on a survey to supplement the aggregate statistical data used in the current paper.

\footnotetext{
${ }^{1}$. Examples of such agencies are the Competition and Markets Authority (CMA) in the UK, DGCOMP in the European Union or the Federal Trade Commission or Department of Justice in the USA.
} 


\subsection{Previous literature}

There is a vast literature on competition and innovation stimulated primarily by the seminal work from Schumpeter $[12,13]$ and Arrow[14]. To avoid repetition, the reader is referred to an invaluable review of this literature by Gilbert[15, 16].

More recently, there is an expanding literature on competition issues in health [17-19] and more specifically using THR as a clinical example. To illustrate, we briefly summarise four recent such papers: Baier et al[20] compare market concentration levels and rates of surgery across districts in Germany, whereas Roos et al[21] use THR to explore the price effects of a hospital merger in The Netherlands. Beckert and Kelly[22] use THR as a common elective procedure to investigate patient choice of provider following the introduction of for-profit providers. Finally, still in the area of competition and providers, Beckert and Collyer [23] examine GPs pre-selected choice-set of provider for elective THR on behalf of their patient using Hospital Episode Statistics (HES) data.

To date however, our own previous work[24] appears to be the only publicly available research on competition issues in terms of the implant suppliers and their interaction with the health provider. We established an emerging picture of the industry's structure using data from the early years of the National Joint Registry (NJR), revealing a very concentrated market in England with just two main suppliers (Stryker and Johnson \& Johnson (J\&)) holding 65\% of the market. One purpose of this paper is to update that previous work.

One other important source and influence on our paper is provided by the European Commission's report on the 2014 merger between two of the world's largest suppliers, Zimmer and Biomet[25]. These firms were only relatively small players ( $3^{\text {rd }}$ and $5^{\text {th }}$ biggest firms) in England and Wales, but were much bigger in other European countries. The Commission required some divestments by the merging firms in these other member states, this was not deemed unnecessary in the UK. We return to the findings of this EC report in section 5 .

\section{Market definition and the nature of the product}

The two main components of a hip implant are the cup and the stem, with a key distinction being made by the method of fixation used i.e. cemented or uncemented. Traditionally, implants are fixed to the bone with cement, however, as an alternative, the surfaces of the implants can be roughened or specifically treated to encourage bone to grow into them, known as uncemented. Sometimes an implant might be a hybrid, where only one part of the implant is fixed with cement. From a competition perspective, a key issue is whether cemented and uncemented compete in the same market. All the signs are that they do. Indeed, the European Commission made precisely this 
judgement when defining the market in its competition investigations of mergers between implant suppliers (notably Zimmer and Biomet[25]). This judgement was based on the recognition that cemented and uncemented implants are seen as substitutes on the demand side, and all main suppliers sell both cemented and uncemented components on the supply side. Note however that this does not necessarily mean they are very close substitutes: surgeons may have a strong preference for uncemented over cemented implants for certain types of patients, and some suppliers may be stronger in cemented while others are stronger in uncemented. We return to this issue below. It is also worth noting that surgeons also need to make a choice between which bearings surface to use, where the bearing surface refers to the area of contact between the two objects. Traditionally, a hardon-soft (metal or ceramic femoral head with a polyethylene cup) has been the preferred choice. However, more recently, hard-on-hard surfaces have been used due to the wearing over time, which takes place with polyethylene. Although choice of bearings surface warrants further investigation too, it is beyond the scope of the work at this stage.

\section{Data Source}

Throughout this paper, we use publicly available data from the NJR for England and Wales. The data are derived from their online annual and subsidiary reports[26-36], which allows us to construct a panel database for 2003-2018 of the market shares of all firms and all prostheses used in the market. However, we subsequently decided to exclude the years 2003 and 2004 due to incomplete coverage as the Registry was beginning to be rolled out.

Figure 1(a) shows the time series for the market shares of cemented and uncemented implants (at this stage not distinguishing between the different suppliers). As can be seen, there was a steady decline in the share of the traditional cemented, from nearly $50 \%$ to little more than $30 \%$ between 2005 and 2010, while there was a complementary rise in the share of uncemented. This was followed by a plateau for two years, before a continuing decline for both types, with the strong emergence of hybrid implants which have been steadily increasing since 2012. However, hybrids still entail cemented and uncemented components, so Figure 1(b) re-computes the graph, but now attributing the hybrids 50:50 to cemented and uncemented. This simplifies the picture, with three distinct phases now apparent: (i) the initial strong penetration of uncemented at the expense of cemented, 20052010, followed by (ii) a slight reversal 2010-2013, but then (iii) broad stability 2013-17. This reveals that as at 2018, there is some way to go if the GIRFT recommendation, that surgeons should switch to cemented, is satisfied. 


\section{Market structure and concentration}

As explained above, our initial representation of the extent of competition in the market follows the approach used by CAs. In the UK, this is clearly set out in the Merger Assessment Guidelines[10] section $5^{2}$. This is heavily reliant in the first instance by the evidence of concentration and market shares and entry of new firms to the market, reflecting the height of barriers to entry.

Derived from the primary NJR data Table 1 establishes the supplier market shares, 2005-2018; this shows the 6 largest accounted for well over 90\% of the market throughout the period. No other supplier had a market share greater than $1 \%$. Between them, the two largest firms, Stryker Osteonics (Stryker) and J\&J (Johnson \&Johnson) currently supply approximately $70 \%$ of the market; the only other sizeable player is Zimmer Biomet with 17\%, which was formed in 2014 following the merger of Zimmer and Biomet. The next three largest (Joint Replacement Instrumentation (JRI), Smith \& Nephew and Corin) account for only $11 \%$ between them.

This upholds, and in fact strengthens the findings from our previous work for 2011[24] where we estimated their combined market share to be approximately $67 \%$. Closer scrutiny reveals that Stryker have in fact slightly increased their market share over the 12 year period, whereas J\&J appear to have lost some (from 2010 to 2016 by about 3\%). Amongst the smaller players, (JRI) has lost market share, while Corin has gained.

\section{HHI concentration index}

In anti-trust, the conventional way of summarising market shares is to employ measures of the concentration of sellers. In broad terms, a concentration index is designed to represent the degree of oligopoly, with higher values indicating higher concentration, i.e. more oligopolistic, markets. The most common measure is the Hirschmann-Herfindahl Index $(\mathrm{HHI})[11,37]$. It is defined as the sum of squared market shares $\left(\mathrm{s}_{\mathrm{i}}\right)$ of all firms [11] p.123-4 [37].

$$
H H I=\Sigma s_{i}^{2} \text { for } i=1 \ldots . . N
$$

So, in a market of $\mathrm{N}$ sellers, if hypothetically all firms were the same size (and therefore each with a market share of $1 / \mathrm{N}$ ), the $\mathrm{HHI}$ would take the value of $1 / \mathrm{N}$. For a monopoly, $\mathrm{HHI}=1$; for duopoly $\mathrm{HHI}=0.5$; and for $\mathrm{N}=100, \mathrm{HHI}=0.01$. Thus, $\mathrm{HHI}$ increases the fewer firms in the market. It also increases the larger the shares of the leading firms; so in the case where $N=100$, suppose the largest firm actually

\footnotetext{
${ }^{2}$ Although the process is spelled out most explicitly in the Merger guidelines, the Authority applies a similar procedure in other areas such as cases of potential monopoly abuse and Market Studies. The current paper is analogous to a Market Study in that the objective is to establish whether there might be a potential competition concern, but there is no initial presumption that there is.
} 
has a market share of $50 \%, \mathrm{HHI}=0.26$, compared to the all equal sized case where the $\mathrm{HHI}$ is 0.01 . In summary, $\mathrm{HHI}$ can vary between 0 and 1, being higher the fewer firms and the more disproportionate the shares of the largest.

For presentational purposes, the index is sometimes expressed in its reciprocal, so called numbers equivalent, form:

$N(H H I)=1 / H H I$

This translates the distribution of firms into a hypothetical number of equal sized firms - the number of equal sized firms who would record that value of $\mathrm{HHI}$ if they had equal shares.

In 2018 , the aggregate $\mathrm{HHI}$ is 0.27 , which is equivalent to a market with 3.64 equal sized firms (table 1). This indicates a highly concentrated market; it easily exceeds the yardstick used by Concentration Authorities to define a highly concentrated market: 0.2 in the EU and UK cases. The Table also reveals a gradual increase over time, partly fuelled by the effects of the worldwide merger between Biomet and Zimmer in 2014, following which the HHI increased from 0.24 to 0.27 in 2015.

In order to identify whether this aggregate picture is replicated in both segments, Tables 2 and 3 disaggregate market shares for the suppliers by implant type: cemented or uncemented. Table 2 clearly indicates the ever-increasing dominance of Stryker in the cemented segment, whose market share grew from $41 \%$ to $57 \%$ over the 14 -year period. In fact, this segment of the market is particularly concentrated with an $\mathrm{HHI}$ of 0.31 rising to 0.39 , and a numbers equivalent of just 2.5 suppliers by 2018. It appears that Stryker gained much of this market share at the expense of its main rival J\&J. The uncemented segment (Table 3 ) is less concentrated than cemented (although still highly concentrated), with an $\mathrm{HHI}$ of around 0.23 , equating to approximately 4.3 suppliers. Here, J\&J's market share grew particularly over the first $4 / 5$ year period at the expense of all the other suppliers.

The market shares and $\mathrm{HHI}$ can be further disaggregated over 4 segments ${ }^{3}$, by separating cups and stems within each of cemented and uncemented. Table 4 provides a concise summary for 2018. This confirms high concentration in all 4 segments, with cemented stem the most pronounced with an $\mathrm{HHI}$ of 0.42 by 2016, an equivalent of just 2.3 suppliers, having risen from 0.35 in 2005; but the picture is similar if less pronounced for cemented cups. The uncemented cups are the least concentrated, having only marginally increased over the period.

\footnotetext{
${ }^{3}$ These tables are in an Appendix, part A
} 
The implication of these disaggregations is that, if cemented and uncemented are only imperfect substitutes, then the aggregate picture in Table 1 actually underestimates the extent of dominance. Stryker has a particularly dominant share of cemented stems (61\%) when compared to any other segment. It also has a very strong market share in cemented cups (49\%). In contrast, J\&J are strikingly dominant in uncemented stems (51\%). It is as if the two major players have each focused on their own areas of strength, ceding the other segment to its rival. How far cemented and uncemented are genuine substitutes will depend, amongst other things, on surgeon preferences.

\section{Market dynamics}

So far, we have focused mainly on static concentration i.e. the level of concentration at specific points in time. We can also observe how that level has changed over time - it is clear that the HHI has tended to increase steadily over this period - both at the aggregate and cemented and uncemented levels.

However, there is more to the dynamics than simply comparing the levels of $\mathrm{HHI}$ at different points in time. A competitive market is one in which firms are continually striving to increase profits and market share, and what matters is whether firms are able to gain (or lose) market share rapidly as a consequence of outperforming (or lagging behind) their rivals. As such, we should look for evidence of significant "churn" within the industry, manifested either as significant entry of new firms and/or turbulence in market shares amongst existing firms. Levels or changes in aggregate market concentration will not necessarily capture that turbulence - in any given year, there will be some gainers and some losers, so the identity of the leaders may change, but the level of concentration might not.

To assess the underlying dynamics in the market, we consider first the evidence on new entry and second the extent of churn in market shares. The former will always be important in any competition agency investigation, but the latter is often overlooked.

\subsection{Entry and Exit}

The data from the NJR in table 5, reveals a very static market with no new firms in any of the four segments. The only activity which has taken place is the exit of three firms, one of which was by acquisition.

\subsection{Churn in market shares}


To capture the extent of churn - the ebb and flow in market shares - we go further than the typical competition authority by introducing a quantitative approach which is novel in this area. This employs the stability of market amongst incumbent suppliers as a measure of the turbulence of competition.

We investigate using the panel data to look at year on year changes in supplier market shares over the 14-year period within each segment. Thus, we regress the supplier market shares against their market shares for the previous year:

$$
x_{i t}=\alpha+6 x_{i t-1}+\varepsilon_{i t}
$$

Where $\alpha$ and $B$ are coefficients and $x_{i t}$ is the market share for supplier $i$ in year $t(2005-2018)$ and $x_{i t-1}$ is the market share for supplier $i$ in the previous year ${ }_{\mathrm{t}-1 .} \varepsilon_{\text {it }}$ is the error term.

In this model, there are two key indicators of the process in competition. 6 , the slope on lagged market share reveals whether there is any underlying tendency for the larger suppliers to grow increasingly at the expense of the smaller ones $(B>1)$, or whether smaller suppliers are able to catch up to some extent $(B<1)$. The second is the variance of the disturbance term relative to the variance of the market share; this will be revealed by the R-squared of the equation: where the R-squared is near to unity, this indicates that all that matters in determining a firm's current market share is its share last year, But where R-squared is small, this suggests that there is much more scope for suppliers to grow or decline due to other non-size-related factors.

We fit the model to a truncated form of the data set, which excludes those smaller suppliers which have only very low shares of less than $0.5 \%$ and appear only intermittently in the NJR. This provides a balanced sample. Two different models are estimated in logged form ${ }^{4}$, the first is a standard panel regression model with random effects. In the second, we use the Arellano-Bond model to manage the potential issues raised by using a lagged dependent variable as a regressor. This violates strict exogeneity due to its correlation with error term; and in the Arellano-Bond method, first differences of the regression equation are taken to eliminate the fixed effects. Then, deeper lags of the dependent variable are used as instruments for differenced lags of the dependent variable (which are endogenous[38]).

The results are reported in tables 6.1 and 6.2 and both point to a market with very little dynamics, in the cemented sector, but rather more in uncemented. Thus, in the random effects model (table 6.1), the $b$ coefficient is significantly greater than 1 for cemented cup and not significantly different from 1 for cemented stem, this indicates very little change in the shares of suppliers from year to year -

\footnotetext{
${ }^{4}$ The logged form is conventional in this context as it provides a test of the law of proportional effects i.e. the whether the proportionate growth of the firm is related to its initial market share.
} 
indeed, if anything, there is a systematic tendency for large suppliers to grow proportionately faster. The magnitudes of the coefficients are robust to using the Arellano-Bond model. In the uncemented sectors, on the other hand ), the 8 coefficient is significantly less than 1 for both cup and Stems in both the random effects and Arellano-Bond models. This indicates a significant tendency for small firms to make some inroads into the leaders' market shares. The within R squared in both models is also close to 1 in all segments, what matters most in determining a supplier's current market share is what it was in the previous period - perhaps reflecting surgeon-loyalty leading to a tendency to opt for no change in their implant preferences.

Ideally, these results would be compared with similar tests using this methodology for other comparator industries, for example, hip implants in other countries. While no such comparative results exist, the most striking conclusion we are able to draw is the difference between the two sectors: using uncemented as a comparator, or control, we see that dynamics in the cemented sector are more or less absent.

\section{An International Perspective}

At a more descriptive level, it is possible to conduct an international comparison using European data published by the EC in its decision report on the 2014 Zimmer/Biomet merger. As mentioned in section 1.2 above, the EC judged that this merger had no anti-competitive concerns in the UK but that it did in other member states in which the two firms had more significant market shares. For present purposes, our main interest is not so much with the EC's decision, but more with the data it reports on the market structure of the industry in other European countries. These are reproduced here in our Table 7, in which we add our own estimates of the firms' shares in England and Wales (taken from our Table 1). This shows that the combined Zimmer-Biomet market share is indeed much lower in England and Wales (typically less than half the European average). But, in contrast, J\&J and particularly Stryker have considerably more market share in England and Wales. In Stryker's case, its market share is almost certainly double its share in other European countries. Bearing in mind Stryker relative strength in the cemented sector, it is likely that its market share is even more out of line with the European average for cemented (which is not reported in the EC report.)

The obvious question is why is the market structure so very different from other European countries? In particular, what explains the unusually dominant share of Stryker in this country? ${ }^{5}$ This, coupled with our finding of lack of dynamics in the cemented sector, raises potential concerns given recent

\footnotetext{
${ }^{5} \mathrm{~A}$ second question, not so relevant for the current paper, is whether the EC was right to allow the emergence of such a large $3^{\text {rd }}$ supplier in the UK. Five years have now passed since the merger, and in light of our findings, we believe it warrants an ex-post evaluation of the EC's decision.
} 
policy recommendations, such as those made by GIRFT, which may have the effect of strengthening Stryker's leading position even further. We return to this in our conclusions.

\section{Innovation}

In the first part of the paper then, we have established that the market is highly concentrated, very little churn in market shares and virtually no entry of new suppliers. All of these features are more pronounced in the cemented segment. In competition economics, this sort of structure would be viewed as potentially indicative of market power and lack of competition. However, evidence on structure alone is insufficient: a full anti-trust examination would also examine how structure impacts and interacts with how the market behaves and performs. In general, this would be assessed by indicators such as price, quality, productivity and innovation. Given the data currently at our disposal, we have chosen to focus on innovation. This is a key indicator for policy purposes, and there is a long tradition of research in 10 , of how competition impacts on innovative performance. The consensus view is that it has a positive impact. See, for example, Cabral [37]. Innovation can be measured in various ways, here we examine (i) the number of new models (or 'brands') introduced on to the market and (ii) their success in penetrating the market. Fortunately, the raw data available in the NJR allows us to document both features very accurately.

\subsection{The number of new models (entrant brands)}

For this purpose, we define a potential entrant brand as one which had achieved a market share of at least $1 \%$ in its segment by 2018 , having not featured in 2005 . From trawls of the NJR annual reports, there have been 59 such brands, however, of these, 12 appear to have been merely re-branding of existing implants (table 7.1), therefore 47 new potential implants were identified. Interestingly, while Stryker and J\&J were responsible for just under half of the re-brands, they accounted for only 6 of the 47 new implants. This could suggest that Stryker and J\&J are focussing on largely fine-tuning their existing dominant brands, while the smaller players are the main source of genuine innovations. Moreover innovation by the smaller firms has been more extensive in the uncemented segment where there were 40 potential new implants and 7 rebrands, compared to 7 potential entrants and 5 rebrands in the cemented segment.

\subsection{Market penetration by the new brands}

Table 7.2 records how successful these new brands have been in securing market share. So, for example, all new brands of cemented cups emerging between 2005 and 2018 had secured $45 \%$ of the cemented cup market by 2018 . However, only $2 \%$ of this was from genuinely new brands, $43 \%$ was from rebrands: on further examination much of this is from the Marathon cup (J\&J) which had a 
market share of $22 \%$ by 2018 and replaced the highly successful Charnley, and the Exeter X3 (Stryker) which had a market share of $18 \%$ by 2018 and replaced the Duration cup. Looking across the whole Table, this confirms that innovation has had much less impact in the cemented segment( $2 \%$ in both cups and stems) than the uncemented, with the same brands in 2005 still leading in 2018 (notably Stryker's Exeter V40). In the uncemented sector, while J\&J's Pinnacle cup and Corail stem continue to hold leading positions ${ }^{6}$, there is some evidence of entrant brands' success: a combined share in both uncemented cups and stems of $10 \% .^{7}$

Taken together these two Tables reveal a striking lack of movement within the cemented segment, compared to the uncemented which could be the impact of a lack of competition. Again, before drawing definite conclusions there is an obvious need for a comparator, ideally what is the experience in other countries, but an international one, and this is a clear priority for future research.

\subsection{Generic Implants}

In recent years there has been an emerging literature on the feasibility of generic brands entry into the market for hip implants[39, 40]; as many of the established brands have come off patent, there is scope for entry of new generics which are similar to the originals by the process of reverse engineering. These generic implants would be cheaper to produce and cheaper for the hospital to purchase, even more so because they would potentially exclude the sales and marketing component of the cost, estimated to be approximately $40 \%[39]$.

Here a possible comparator is the Pharmaceutical sector, in which (Atrey et al), generics are fully established ${ }^{8}$, and this has facilitated competition in the market. The process of regulation in medical devices is much less stringent than for the pharmaceutical market, for example in Europe a supplier of a new device need only demonstrate 'equivalence data' whereby they have demonstrated that the implant is similar enough in design to an existing implant in order for it be provided with a CE mark and approved for use in clinical practice[41]. As such, there has been considerable resistance from some surgeons to the use of generics, specifically with regards to the testing the processes of production and the tolerances of replicas. There is also further resistance regarding the withdrawal of

\footnotetext{
${ }^{6}$ Implants disaggregated down to the four segments is available in the Appendix, part B

${ }^{7}$ The fact that entry in uncemented stems is less than in uncemented cups is consistent with a feature revealed in figure 1, i.e. the trend to the hybrid implant - using an uncemented cup and a cemented stem.

8 In pharma, the drug is defined as identical or bioequivalent to a brand name drug in dosage form, safety, strength, route of administration, quality, performance characteristics and intended use, thus genuine replication of the product is possible..$^{\mathbf{2 0}}$
} 
sales and marketing i.e. a supplier presence in the Operating Theatre associated with the use of generic implants.

In fact, we have identified only one generic supplier within our NJR data-set: Orthimo, who manufactured the OPTISTEM XTR and OPTIHEAD XTR/Opticup. According to 'Beyond Compliance ${ }^{9}[42]$, the date of their first use was 2014 , where they were given an 'unclassified' rating. The rate of implantation rose from 2 (cup and stem) in 2014, to 83 and 101 cup and stem respectively by 2016 . However, by 2017, Orthimo had gone into liquidation with no specific reason specified. Since Orthimo, there does not appear to have been any new generic companies entering the market in England and Wales. However, some of the newer implants manufactured by the established companies may well be 'direct copies' of the existing well established brands and as such, these could be deemed a generic implant. In that case, is this just a branded generic market? Further research is required.

\subsection{Other areas of Innovation}

Finally, we briefly explore whether there are other areas within hip implant surgery in which suppliers are choosing to focus their innovative attention on.

There does appear to have been a re-focus in attention by some suppliers towards establishing contracts with the hospitals themselves to provide procurement and after sales services. Johnson \& Johnson Managed Services (part of Johnson \& Johnson Finance Limited) have set up a programme with Guy's and St Thomas' Foundation Trust where they will provide a team to manage the supply chain, and work with the trust's clinical and non-clinical staff. They aim to develop eight new operating theatres by 2020 [43]. Smith \& Nephew have also developed a 'spin-off' arm, Syncera ${ }^{10}$, who are offering interactive operating theatre training on technology and procedure. Although this cuts out the sales and marketing costs, it could be 'tying' the hospital into using Smith and Nephew products. OrthoDirectUSA[44], is a U.S based company offering a 'middle man' service which they claim will cut out the sales and marketing costs imposed by suppliers whilst still offering the same product. They interact with both the hospital and supplier using their own learning and development programme, currently this is only available in the USA. These innovations are still in their early stages and there are clearly many other areas in which innovation is taking place within the clinical field of total hip replacement surgery. For example, the use of robotics in the operating theatre, using imaging to assess correct implant type both prior to and during surgery and the use of 3D printers to produce custom

\footnotetext{
${ }^{9}$ Beyond Compliance is an independent panel, working with manufacturers to assess the relative risk of a new product. http://www.beyondcompliance.org.uk/

${ }^{10}$ At the time of writing, the website for Syncera is no longer available.
} 
made implants. At this point, all of these technologies are relatively new and subject of on-going clinical debate in terms of safety and effectiveness $[45,46]$.

So it is possible that the apparent lack of innovation in the implants themselves is evidence that sufficient implant innovation has already occurred and that technology is moving on to other areas. However, it may also indicate that suppliers have identified that the other areas within the field (discussed above) may provide a more lucrative option for them to focus on.

\section{Main findings and future work}

We have found a highly concentrated oligopolistic market with a static market structure, in which two suppliers have a combined market share of approximately $70 \%$ persistently over this period. Over time, there has been really only two detectable changes: an increasing dominance of Stryker, the leading supplier in the cemented sector, and a merger between the much smaller $3^{\text {rd }}$ and $4^{\text {th }}$ largest suppliers, Zimmer and Biomet. The market seems largely devoid of dynamics: there has been very little entry or exit. Moreover, the market shares of the incumbents show remarkably little turbulence: large firms remain large, and small firms remain small - no real evidence of thriving competition where efficient firms can gain at the expense of the inefficient. Viewed through the eyes of a competition economist, such a structure might be indicative of weak competition, and certainly deserving of further investigation. This is particularly true for the cemented part of the market.

Turning to innovation, we have identified only limited evidence of the emergence and growth of new brands. The smaller suppliers have had little success in introducing new brands, and the main two suppliers appear to have concentrated on updating existing brands. There is also little evidence of competition from generics, in contrast to in many parts of the pharmaceutical sector.

These findings are not necessarily evidence of a weakly performing anti-competitive market. Alternative, less problematic, explanations are possible. For example, this may merely be a market which is now very mature and all of the major technical advances have been made. Nevertheless, further research is definitely called for to help distinguish between alternative explanations. The implications are important, not only for competition policy, but also for the prevailing guidance to surgeons that they should employ cemented fixations[3, 7-9].

To pursue this in the future, as suggested by Deere at al[47], we propose to carry out a mixed methods survey of decision making by surgeons, procurement departments and suppliers, to better understand who is making the decisions about implant choice and on what basis the choice is made. Recent policy interventions such as price benchmarking and GIRFT have put into place guidance which is intended to help the NHS secure a better deal in its purchasing and procurement (amongst other things). 
However, these deals need to not only negotiate on achieving similar prices for all hospitals, but also lower prices. Similarly advice to specialise increasingly on cemented prostheses raises the risk is likely to further increase Stryker's already dominant position, with even less price competition, Suppliers with a focus on the uncemented market might also suffer following these recommendations, which might explain why companies such as JRI are already looking to expand in the Asian markets. There could also be a potential danger in focussing on cemented implants as patient demographics may change over time with people living longer and younger more active people potentially requiring more hip replacements earlier (i.e. the gold standard implant might not work for them). Our proposed survey of decision making, alongside an updated analysis of implantation rates will enable us to drill down deeper at the micro-level to better understand whether the recent policy recommendations might further add to what is already a highly concentrated market.

\section{Notes}

All data were derived from the NJR annual reports/supplementary information. The NJR was established in 2003 and collects data on hip, knee, shoulder, ankle and elbow replacements carried out in the NHS and independent health care settings. For 2005 only the top 20 brands were reported for each sub section. Thus we have supplemented the 2005 data with primary data used in previous research i.e. the data differs slightly from after the top 20.

\section{Acknowledgements}

We would like to thank Professor Jon Sussex for his invaluable discussion of our paper at HESG, Norwich 2019. We would also like to thank the audience at HESG, 2019 for their useful feedback. Thank you to Professor Paula Lorgelly, Professor Ruth Hancock and Professor Stephen Davies for their comments on the paper. Finally thanks to the patients who provided the data to the National Joint Registry.

\section{References}

1. National Audit Office, Hip Replacements: Getting it right first time, House of Commons, Editor. 2000.

2. National Audit Office, The procurement of consumables by NHS acute and Foundation Trusts, Department of Health, Editor. 2011.

3. Briggs, T., A national review of adult elective orthopaedic services in England - GETTING IT RIGHT FIRST TIME, in British Orthopaedics Association. 2015.

4. Green, P., Efficiency Review - Key findings and recommendations. 2010. 
5. Lord Carter of Coles, Operational productivity and performance in English NHS acute hospitals: Unwarranted variations, Department of Health, Editor. 2016.

6. National Institute for Health and Care Excellence, Total hip replacement and resurfacing arthroplasty for end-stage arthritis of the hip,, in Technology appraisal guidance [TA304],. 2014.

7. Cook, R., T. Lamont, and R. Martin, A traditional hip implant is as effective as newer types for people over 65. BMJ, 2019. 366: p. 14230.

8. Fawsitt, C.G., et al., Choice of Prosthetic Implant Combinations in Total Hip Replacement: CostEffectiveness Analysis Using UK and Swedish Hip Joint Registries Data. Value in Health, 2019. 22(3): p. 303-312.

9. E., M., et al., THE CHOICE BETWEEN HIP PROSTHETIC IMPLANTS IN TOTAL HIP ARTHROPLASTY: A COST-EFFECTIVENESS MODEL USING UK AND SWEDISH HIP JOINT REGISTRIES DATA. Orthopaedic Proceedings, 2018. 100-B(SUPP_3): p. 8-8.

10. Office of Fair Trading \& Competition Commission., Merger Assessment Guidelines, 2010.

11. Motta M, Market power and welfare: Introduction, in Competition Policy - Theory and Practice. 2004, Cambridge University Press. p. 30.

12. Schumpeter, J.A., Capitalism, socialism, and democracy. 1942.

13. Schumpeter, J.A. and R. Opie, The theory of economic development; an inquiry into profits, capital, credit, interest, and the business cycle. 1934, Cambridge, Mass.: Harvard University Press.

14. Arrow, K., The Economic Implications of Learning by Doing. Review of Economic Studies, 1962. 29(3): p. 155-173.

15. Gilbert, R., Looking for Mr. Schumpeter: Where Are We in the Competition-Innovation Debate?, in Innovation Policy and the Economy, Volume 6. 2006, National Bureau of Economic Research, Inc. p. 159-215.

16. Gilbert, R. and D.M. Newbery, Preemptive Patenting and the Persistence of Monopoly. American Economic Review, 1982. 72(3): p. 514-26.

17. Barros, P.P., et al., Competition among health care providers: helpful or harmful? The European Journal of Health Economics, 2016. 17(3): p. 229-233.

18. Propper, C., Competition in health care: lessons from the English experience. Health Economics, Policy and Law, 2018. 13(3-4): p. 492-508.

19. Zweifel, P., Competition in the healthcare sector: a missing dimension. The European Journal of Health Economics, 2017. 18(2): p. 135-138.

20. Baier, N., L.-M. Sax, and L. Sundmacher, Trends and regional variation in rates of orthopaedic surgery in Germany: the impact of competition. The European Journal of Health Economics, 2019. 20(1): p. 163-174.

21. Roos, A.-F., et al., Price effects of a hospital merger: Heterogeneity across health insurers, hospital products, and hospital locations. Health Economics, 2019. 28(9): p. 1130-1145.

22. Beckert W, K.E., . Divided by Choice? For-Profit Providers, Patient Choice and Mechanisms of Patient Sorting in the English National Health Service., in IFS Working Paper Series, I.f.F. Studies, Editor. 2017. p. 1-57.

23. Beckert, W., Choice in the presence of experts: The role of general practitioners in patients' hospital choice. Journal of Health Economics, 2018. 60: p. 98-117.

24. C. Davies, An analysis of choice: A case study on hip prostheses, in Norwich Medical School. 2011, University of East Anglia: Norwich. p. p.21.

25. European Commission, D.C., Case M.7265 - Zimmer/Biomet, in Merger Procedure Regulation (EC) 139/2004. 2015: Brussels.

26. National Joint Registry, Prostheses used in hip, knee, ankle, elbow and shoulder replacement procedures 2013, in 11th Annual Report. 2014.

27. National Joint Registry, Prostheses used in hip, knee, ankle, elbow and shoulder replacement procedures 2014, in 12th Annual Report. 2015. 
28. National Joint Registry, Prostheses used in hip, knee, ankle, elbow and shoulder replacement procedures 2015, in 13th Annual Report. 2016.

29. National Joint Registry, Prostheses used in hip, knee, ankle, elbow and shoulder replacement procedures 2016, in 14th Annual Report. 2017.

30. National Joint Registry, Prostheses used in hip, knee and ankle replacement procedures 2011, in 9th Annual Report. 2012.

31. National Jointr Registry, Prostheses used in hip, knee, ankle, elbow and shoulder replacement procedures 2012, in 10th Annual Report. 2013.

32. National Joint Registry., Prostheses used in hip and knee replacement procedures 2007, in 5th Annual Report. 2008.

33. National Joint Registry, Prostheses used in hip and knee replacement procedures, 2008 , in 6 th Annual Report. 2009.

34. National Joint Registry, Prostheses used in hip and knee replacement procedures, 2009, in 7th Annual Report. 2010.

35. National Joint Registry, Prostheses used in hip, knee and ankle replacement procedures, 2010, in 8th Annual Report. 2011.

36. National Joint Registry, 4th Annual Report - Prostheses used 2006 contained within main report . in 4th Annual Report, 2007.

37. Cabral L.M.B., Introduction to Industrial Organization. Vol. 2. 2017, Massachusetts: MIT Press,.

38. Cameron A.C., a.T.P.K., Microeconometrics using Stata,. Vol. Revised Edition. 2010: Stata Press,.

39. Atrey A., H.S., Gosling O., Porteous M.J.L. \& Haddad F.S., The manufacture of generic replicas of implants for arthroplasty of the hip and knee - is it regulated and will it save money? The Bone and Joint Journal, 2016. 98-B(7): p. 892-900.

40. Orthoworld. Orthopaedic industry annual report. Focus on joint replacement.,. 2012.

41. Royal College of Surgeons, Surgical Innovation, New Techniques and Technologies - A Guide to Good Practice. 2019.

42. Beyond Compliance. Beyond Compliance. Protecting Patients, Supporting Innovation,. 2019; Available from: https://www. beyondcompliance.org.uk/.

43. Carding, N., Trust awards $£ 300 m$ orthopaedics contract to US firm, H.S. Journal, Editor. 2017. 44. OrthoDirect USA. OrthoDirect USA, . 2019; Available from: https://www.orthodirectusa.com.

45. Mahase, E., Royal College of Surgeons warns against "mavericks" in new innovation guideline. BMJ, 2019. 365: p. 12170.

46. Dyer, C., Robot assisted surgery is blamed for heart patient's death. BMJ, 2018. 363: p. k4791.

47. Deere, K.C., et al., Assessing the non-inferiority of prosthesis constructs used in hip replacement using data from the National Joint Registry of England, Wales, Northern Ireland and the Isle of Man: a benchmarking study. BMJ Open, 2019. 9(4): p. e026685. 
Figure 1(a) ${ }^{11}$ market shares of implants by type -2005 to 2018

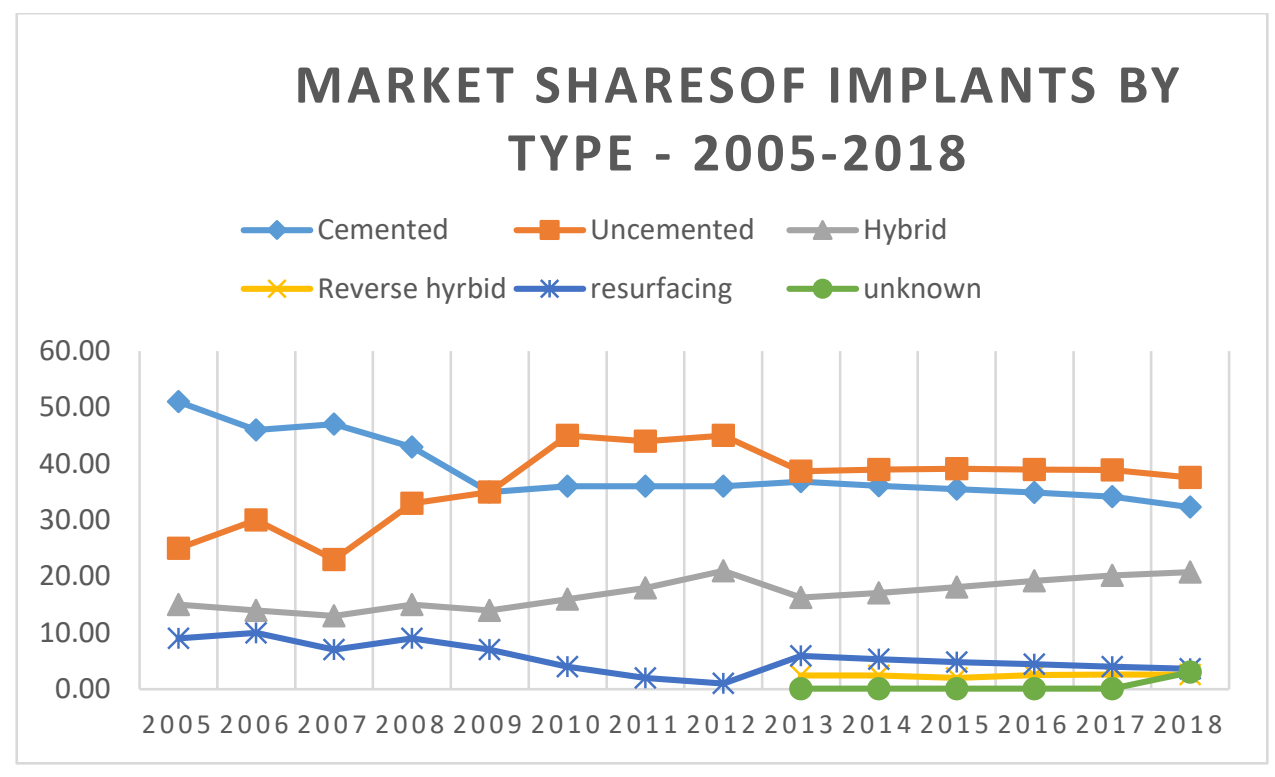

Figure 1 (b) market shares by implant type netting out for hybrids, 2005-2018

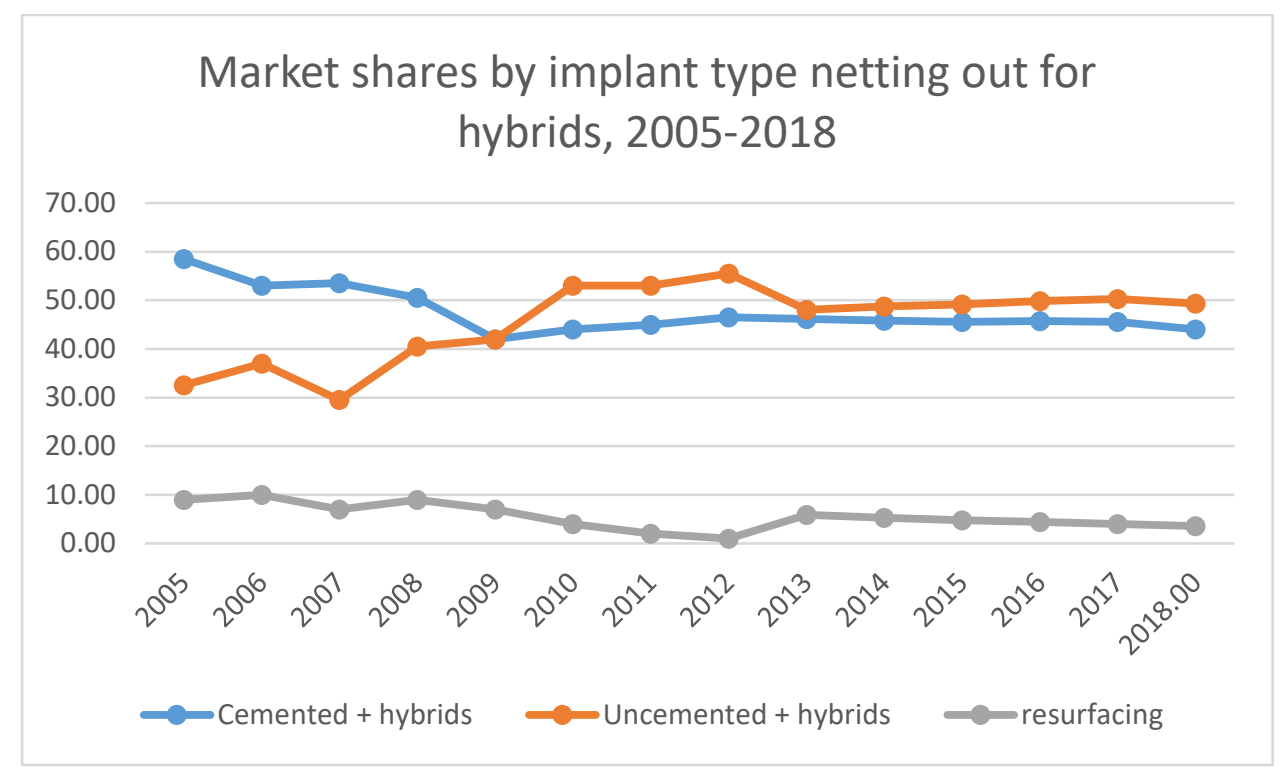

${ }^{11}$ The data source for this and all subsequent figures and tables except Table 8, is raw data from the NJR, collated and manipulated by the author http://www.njrreports.org.uk/ 
Table 1- Market Shares of leading suppliers in England and Wales

\begin{tabular}{|c|c|c|c|c|c|c|c|c|c|c|c|c|c|c|}
\hline & 2005 & 2006 & 2007 & 2008 & 2009 & 2010 & 2011 & 2012 & 2013 & 2014 & 2015 & 2016 & 2017 & 2018 \\
\hline Stryker & 0.32 & 0.33 & 0.33 & 0.33 & 0.34 & 0.32 & 0.34 & 0.34 & 0.37 & 0.35 & 0.35 & 0.36 & 0.36 & 0.38 \\
\hline J\&J & 0.34 & 0.32 & 0.33 & 0.32 & 0.33 & 0.34 & 0.33 & 0.32 & 0.30 & 0.32 & 0.32 & 0.31 & 0.32 & 0.31 \\
\hline Zimmer Biomet (combined)* & 0 & 0 & 0 & 0 & 0 & 0 & 0 & 0 & 0 & 0 & 0.19 & 0.19 & 0.18 & 0.17 \\
\hline Zimmer & 0.11 & 0.12 & 0.12 & 0.11 & 0.10 & 0.11 & 0.11 & 0.11 & 0.11 & 0.12 & 0 & 0 & 0 & 0 \\
\hline Biomet & 0.05 & 0.05 & 0.06 & 0.05 & 0.06 & 0.07 & 0.07 & 0.07 & 0.06 & 0.06 & 0 & 0 & 0 & 0 \\
\hline JRI & 0.08 & 0.08 & 0.07 & 0.07 & 0.07 & 0.07 & 0.06 & 0.06 & 0.06 & 0.05 & 0.04 & 0.04 & 0.03 & 0.02 \\
\hline Smith \& Nephew & 0.06 & 0.06 & 0.05 & 0.07 & 0.06 & 0.05 & 0.03 & 0.04 & 0.04 & 0.05 & 0.04 & 0.04 & 0.05 & 0.06 \\
\hline Corin & 0.01 & 0.01 & 0.01 & 0.01 & 0.01 & 0.01 & 0.01 & 0.02 & 0.02 & 0.02 & 0.03 & 0.03 & 0.03 & 0.03 \\
\hline All others*** & 0.03 & 0.03 & 0.03 & 0.04 & 0.04 & 0.04 & 0.05 & 0.05 & 0.04 & 0.04 & 0.03 & 0.03 & 0.03 & 0.03 \\
\hline $\mathrm{HHI}$ & 0.24 & 0.24 & 0.24 & 0.24 & 0.24 & 0.24 & 0.24 & 0.24 & 0.25 & 0.24 & 0.27 & 0.27 & 0.27 & 0.27 \\
\hline No's equivalent & 4.11 & 4.16 & 4.11 & 4.21 & 4.11 & 4.13 & 4.08 & 4.18 & 4.04 & 4.08 & 3.75 & 3.77 & 3.70 & 3.64 \\
\hline
\end{tabular}

Table 2- Market shares of leading suppliers for cemented fixation

\begin{tabular}{|c|c|c|c|c|c|c|c|c|c|c|c|c|c|c|}
\hline & 2005 & 2006 & 2007 & 2008 & 2009 & 2010 & 2011 & 2012 & 2013 & 2014 & 2015 & 2016 & 2017 & 2018 \\
\hline Stryker & 41 & 43 & 46 & 51 & 54 & 55 & 57 & 59 & 61 & 60 & 58 & 58 & 57 & 57 \\
\hline J\&J & 36 & 33 & 28 & 24 & 22 & 22 & 22 & 21 & 19 & 20 & 21 & 20 & 21 & 22 \\
\hline Zimmer Biomet (combined)* & 0 & 0 & 0 & 0 & 0 & 0 & 0 & 0 & 0 & 0 & 17 & 17 & 17 & 16 \\
\hline Zimmer & 9 & 11 & 12 & 11 & 11 & 12 & 12 & 11 & 11 & 15 & 0 & 0 & 0 & 0 \\
\hline Biomet & 5 & 5 & 7 & 5 & 5 & 4 & 4 & 3 & 3 & 2 & 0 & 0 & 0 & 0 \\
\hline Corin & 1 & 1 & 1 & 1 & 1 & 1 & 1 & 1 & 1 & 1 & 1 & 1 & 1 & 2 \\
\hline JRI & 2 & 1 & 1 & 1 & 1 & 1 & 0 & 1 & 1 & 0 & 1 & 0 & 1 & 1 \\
\hline Mathys & 0 & 0 & 0 & 1 & 1 & 1 & 1 & 1 & 1 & 1 & 0 & 0 & 0 & 0 \\
\hline Waldemar Link & 2 & 1 & 1 & 1 & 1 & 1 & 0 & 0 & 0 & 0 & 0 & 0 & 0 & 0 \\
\hline B Braun/Aesculap & 0 & 0 & 0 & 0 & 0 & 0 & 0 & 1 & 1 & 1 & 1 & 1 & 1 & 1 \\
\hline All others** & 4 & 5 & 4 & 5 & 4 & 3 & 3 & 2 & 2 & 0 & 1 & 3 & 2 & 1 \\
\hline HHI & 0.31 & 0.31 & 0.31 & 0.33 & 0.35 & 0.36 & 0.39 & 0.4 & 0.43 & 0.41 & 0.4 & 0.4 & 0.39 & 0.39 \\
\hline Numbers equivalent & 3.22 & 3.21 & 3.21 & 2.99 & 2.83 & 2.76 & 2.59 & 2.48 & 2.33 & 2.41 & 2.51 & 2.49 & 2.56 & 2.54 \\
\hline
\end{tabular}

*combined market share following 2014 merger. ${ }^{* *}$ All others - with a market share $<1 \%$ 
Table 3 - Market shares of leading suppliers for uncemented fixation

\begin{tabular}{|c|c|c|c|c|c|c|c|c|c|c|c|c|c|c|}
\hline & 2005 & 2006 & 2007 & 2008 & 2009 & 2010 & 2011 & 2012 & 2013 & 2014 & 2015 & 2016 & 2017 & 2018 \\
\hline J\&J & 29 & 32 & 39 & 40 & 41 & 42 & 41 & 40 & 40 & 41 & 42 & 41 & 41 & 38 \\
\hline Stryker & 18 & 18 & 17 & 16 & 18 & 16 & 17 & 15 & 16 & 15 & 16 & 17 & 20 & 22 \\
\hline $\begin{array}{l}\text { Zimmer Biomet } \\
\text { (combined)* }\end{array}$ & 0 & 0 & 0 & 0 & 0 & 0 & 0 & 0 & 0 & 0 & 20 & 20 & 19 & 18 \\
\hline Zimmer & 15 & 14 & 13 & 11 & 10 & 10 & 11 & 10 & 11 & 11 & 0 & 0 & 0 & 0 \\
\hline Biomet & 5 & 5 & 5 & 6 & 7 & 8 & 9 & 9 & 9 & 8 & 0 & 0 & 0 & 0 \\
\hline Corin & 0 & 0 & 0 & 0 & 0 & 1 & 2 & 3 & 3 & 4 & 4 & 4 & 4 & 4 \\
\hline JRI & 20 & 18 & 15 & 12 & 12 & 11 & 10 & 9 & 10 & 9 & 7 & 6 & 5 & 4 \\
\hline Mathys & 0 & 0 & 1 & 1 & 0 & 0 & 0 & 0 & 0 & 1 & 1 & 1 & 1 & 0 \\
\hline B Braun/Aesculap & 1 & 1 & 1 & 1 & 1 & 1 & 1 & 2 & 1 & 1 & 1 & 1 & 1 & 1 \\
\hline Smith \& Nephew & 10 & 9 & 8 & 8 & 7 & 6 & 3 & 5 & 6 & 7 & 6 & 7 & 7 & 10 \\
\hline Microport & 1 & 0 & 0 & 1 & 2 & 2 & 2 & 2 & 1 & 1 & 1 & 1 & 1 & 1 \\
\hline All others** & 1 & 2 & 2 & 4 & 1 & 2 & 3 & 4 & 3 & 3 & 2 & 3 & 1 & 2 \\
\hline $\mathrm{HHI}$ & 0.19 & 0.2 & 0.22 & 0.22 & 0.24 & 0.24 & 0.23 & 0.22 & 0.22 & 0.22 & 0.23 & 0.23 & 0.23 & 0.23 \\
\hline Numbers equivalent & 5.26 & 5.00 & 4.55 & 4.55 & 4.17 & 4.17 & 4.35 & 4.55 & 4.55 & 4.55 & 4.35 & 4.42 & 4.35 & 4.35 \\
\hline
\end{tabular}

${ }^{*}$ see table $1 .{ }^{* *}$ All others - with a market share of $<1 \%$

Table 4 - Leaders market shares by segment (2018)

\begin{tabular}{|l|c|c|c|c|}
\hline & cemented cup & cemented stem & uncemented cup & uncemented stem \\
\hline Stryker & 49 & 61 & 29 & 10 \\
\hline J\&J & 34 & 14 & 31 & 51 \\
\hline Zimmer & 9 & 18 & 14 & 5 \\
\hline Biomet & 3 & 1 & 5 & 11 \\
\hline JRI & 0 & 1 & 3 & 5 \\
\hline Corin & 0 & 2 & 4 & 4 \\
\hline Smith \& Nephew & 1.1 & 1 & 8 & 11 \\
\hline All others & 3.9 & 2 & 6 & 3 \\
\hline HHI & 0.37 & 0.42 & 0.22 & 0.3 \\
\hline Numbers equivalent & 2.69 & 2.36 & 4.59 & 3.36 \\
\hline
\end{tabular}


Table 5 - Suppliers who have entered or left the market, 2005-2018

\begin{tabular}{|l|l|l|l|}
\hline Supplier & Exitor*/entrant** & Year & Reason for exit \\
\hline \multicolumn{4}{|c|}{ Cemented cup } \\
\hline \multicolumn{4}{|c|}{ Cemented stem } \\
\hline Waldemar Link & exitor & 2016 & unknown \\
\hline \multicolumn{4}{|c|}{ Uncemented cup } \\
\hline Wright Medical & exitor & 2011 & acquired by Microport in 2013 \\
\hline Endoplus & exitor & Uncemented stem & unknown \\
\hline \multicolumn{4}{|c|}{2009} \\
\hline Wright Medical & exitor & acquired by Microport in 2013 \\
\hline
\end{tabular}

* exit - where a supplier is no longer present in the segment of the market in 2018 , but had been active for at least 2 consecutive years

**entrant - where a supplier entered the segment market and remained there for at least 2 consecutive years since 2005

Table 6.1 Stability of market shares of incumbents, Panel model with random effects

\begin{tabular}{|c|c|c|c|c|c|c|c|}
\hline & $\begin{array}{l}\text { Lagged } \\
\text { Coefficient }\end{array}$ & $\begin{array}{l}\text { Standard } \\
\text { Error }\end{array}$ & $\begin{array}{l}\text { Intercept } \\
\text { Term }\end{array}$ & $\begin{array}{l}\text { Standard } \\
\text { Error }\end{array}$ & $\begin{array}{l}\text { Within R } \\
\text { squared }\end{array}$ & $\begin{array}{l}\text { No. } \\
\text { Observations }\end{array}$ & No. Suppliers \\
\hline Cem Cup & 1.11 & 0.03 & 0.22 & 0.10 & 0.858 & 90 & 7 \\
\hline Cem Stem & 0.97 & 0.03 & -0.08 & 0.08 & 0.656 & 78 & 6 \\
\hline Uncem Cup & 0.94 & 0.03 & -0.16 & 0.08 & 0.7794 & 104 & 8 \\
\hline Uncem Stem & 0.9 & 0.03 & -0.24 & 0.08 & 0.8 & 91 & 7 \\
\hline
\end{tabular}

Table 6.2 Stability of market shares of incumbents, Arellano-Bond Model

\begin{tabular}{|c|c|c|c|c|c|c|}
\hline & $\begin{array}{l}\text { Lagged } \\
\text { Coefficient }\end{array}$ & Standard Error & Intercept Term & Standard Error & $\begin{array}{l}\text { No. } \\
\text { Observations }\end{array}$ & No. Suppliers \\
\hline Cem Cup & 1.19 & 0.19 & 0.48 & 0.55 & 83 & 7 \\
\hline Cem Stem & 0.92 & 0.07 & -0.21 & 0.19 & 72 & 6 \\
\hline Uncem Cup & 0.83 & 0.01 & -0.44 & 0.08 & 96 & 8 \\
\hline Uncem Stem & 0.81 & 0.03 & -0.46 & -0.07 & 84 & 7 \\
\hline
\end{tabular}


Table 7.1 - Brand entrants and re-branding of existing implants into the top 20 by segment

\begin{tabular}{|c|c|c|c|c|c|}
\hline Supplier & Brand & Implant Type & Entrant/Rebrand & Year introduced & Replaced branc \\
\hline $\begin{array}{l}\text { Adler } \\
\text { Orthopaaedics }\end{array}$ & FIXA Duplex & Cemented cup & Entrant & 2007 & \\
\hline Dedienne Sante & Ades & Cemented cup & Entrant & ? & \\
\hline Serf & Novae Stick & Cemented Cup & Entrant & $?$ & \\
\hline JRI & Aeon & Cemented Cup & Rebrand & & Furlong \\
\hline Stryker & Exeter X3 & Cemented Cup & Rebrand & & Duration \\
\hline J\&J & Marathon & Cemented Cup & Rebrand & & Charnley \\
\hline Stryker & No $1125 \mathrm{~mm}$ & Cemented Stem & Rebrand & & Restoration? \\
\hline Microport & Profemur SM & Cemented Stem & Entrant & 2005 & \\
\hline Medacta UK Ltd & AMI stem-C & Cemented Stem & Entrant & $?$ & \\
\hline Corin & Trinity 2 & Uncemented cup & Rebrand & & Dc fit \\
\hline J\&J & Deltamotion & Uncemented cup & Entrant & 2008 & \\
\hline $\mathrm{J} \& \mathrm{~J}$ & Pinnacle & Uncemented cup & Rebrand & 2007 & Duraloc \\
\hline Lima & Delta one TT & Uncemented cup & Entrant & 2007 & \\
\hline Mathys & RM Pressfit & Uncemented cup & Entrant & 2009 & \\
\hline Medacta & Versafit CC trio & Uncemented cup & Entrant & ? 5A ODEP rating & \\
\hline Medacta & MPACT & Uncemented cup & Entrant & ? 5A ODEP rating & \\
\hline Orthodynamics & Novae & Uncemented cup & Entrant & ? 5A ODEP rating & \\
\hline Smith \& Nephew & R3 cementless & Uncemented cup & Rebrand & 2007 & Bicon or EPF plt \\
\hline Zimmer Biomet & G7 Cementelss acetabular & Uncemented cup & Entrant & ? 5A ODEP rating & \\
\hline Zimmer Biomet & Avenir Muller & Uncemented stem & Entrant & ? 7A ODEP rating & \\
\hline Zimmer Biomet & MP revision & Uncemented stem & Entrant & $?$ & \\
\hline Symbios & Evolution & Uncemented stem & Entrant & 2011 & \\
\hline Symbios & SPS Ha & Uncemented stem & Entrant & ? 3A ODEP rating & \\
\hline Stanmore (Stryker) & METS & Uncemented stem & Entrant & $?$ & \\
\hline Smith \& Nephew & Anthology & Uncemented stem & Entrant & 2005 & \\
\hline Smith \& Nephew & Redapt & Uncemented stem & Entrant & $?$ & \\
\hline Peter Brehm (JRI) & Peter Brehm revision & Uncemented stem & Entrant & $?$ & \\
\hline Microport & Profemur L Classic & Uncemented stem & Rebrand & 2012 & Ancafit \\
\hline Microport & Profeumr TL Classic & Uncemented stem & Entrant & 2007 & \\
\hline Microport & Profemur TL & Uncemented stem & Entrant & 2007 & \\
\hline Medacta & AMI-stem H & Uncemented stem & Rebrand & 2009 & AMIS \\
\hline Medacta & AMI stem H Proximal & Uncemented stem & Entrant & $?$ & \\
\hline
\end{tabular}




\begin{tabular}{|l|l|l|l|l|l|}
\hline Medacta & SMS & Uncemented stem & Entrant & 2015 \\
\hline Lima & H_Max S Monobloc & Uncemented stem & Entrant & 2009 & \\
\hline Lima & Master SL & Uncemented stem & Entrant & 2014 & \\
\hline Lima & Lima revision & Uncemented stem & Entrant & $?$ & \\
\hline JRI & Furlong Evolution & Uncemented stem & Entrant & $?$ & \\
\hline JRI & Furlong HAC revision & Uncemented stem & Entrant & $?$ & \\
\hline Implantcast & Mutars & Uncemented stem & Entrant & $?$ & \\
\hline J\&J & Trilock & Uncemented stem & Entrant & $?$ & \\
\hline J\&J & Corail Revision & Uncemented stem & Entrant & $?$ & \\
\hline J\&J & Reclaim & Uncemented stem & Entrant & $?$ & \\
\hline J\&J & LPS & Uncemented stem & Entrant & $?$ & \\
\hline Corin & Metafix & Uncemented stem & Entrant & 2007 & \\
\hline Corin & Trifit & Uncemented stem & Entrant & 2012 \\
\hline Corin & Mini hip & Uncemented stem & Entrant & 2008 \\
\hline Zimmer Biomet & Arcos cone & Uncemented stem & Entrant & $?$ \\
\hline
\end{tabular}

Definitions: A 'true entrant' is defined as a brand which has achieved a market share of at least $1 \%$ in its segment by 2018 , having not featured in 2005 . It is then verified by checking the date of when the implant was introduced through the ODEP website, where an implant is listed as introduced before 2005 it is no longer classed as a true entrant. Where a date is not provided by the ODEP website, the ODEP rating is then used, which has a year component detailing how long the data has been collected for. Where no information is provided by ODEP, an assumption has been based on the pattern of market shares i.e. very low levels of market share which feature irregularly (pop in and out) indicate a non-genuine entrant.

Rebrands are defined as an update of an existing implant but with a new name. Potential 'new entrants' were eye balled alongside 'exitor' brands or those with fast dropping market shares by the same manufacturer, to identify whether the new entrant looks to be replacing an existing one.

These decisions are author determined only and should be subject to more rigorous analysis and discussions with manufacturers and clincians.

Table 7.2- Combined market shares grouped as rebrands and 'genuine' new brands

\begin{tabular}{|l|r|r|r|}
\hline Type & Total & Rebrands & \multicolumn{1}{c|}{ New brand } \\
\hline Cemented cup & 0.42 & 0.4 & 0.02 \\
\hline Cemented stem & 0.06 & 0.04 & 0.02 \\
\hline Uncemented cup & 0.31 & 0.2 & 0.1 \\
\hline Uncemented stem & 0.11 & 0.00 & 0.1 \\
\hline
\end{tabular}


Table 8 - A European comparison of the leading suppliers' market shares, 2013

\begin{tabular}{|l|c|c|c|c|c|c|}
\hline & Zimmer & Biomet & Zimmer Biomet & J\&J & Stryker & Smith \& Nephew \\
\hline Austria & $20-30$ & $5-10$ & $30-40$ & $10-20$ & $5-10$ & $5-10$ \\
\hline Czech & $20-30$ & $10-20$ & $40-50$ & & & \\
\hline Denmark & $10-20$ & $30-40$ & $50-60$ & $20-30$ & $10-20$ & $5-10$ \\
\hline Finland & $10-20$ & $20-30$ & $40-50$ & $30-40$ & $10-20$ & $5-10$ \\
\hline Germany & $30-40$ & $0-5$ & $30-40$ & $10-20$ & & $10-20$ \\
\hline Lithuania & $10-20$ & $30-40$ & $50-60$ & $20-30$ & $10-20$ & $5-10$ \\
\hline The Netherlands & $20-30$ & $20-30$ & $50-60$ & $10-20$ & $10-20$ & $10-20$ \\
\hline Portugal & $10-20$ & $10-20$ & $30-40$ & $20-30$ & $10-20$ & $10-20$ \\
\hline Romania & $60-70$ & $10-20$ & $70-80$ & $20-30$ & $5-10$ & $5-10$ \\
\hline Slovenia & $30-40$ & $10-20$ & $40-50$ & $20-30$ & $5-10$ & $5-10$ \\
\hline Spain & $20-30$ & $5-10$ & $30-40$ & $10-20$ & $10-20$ & $10-20$ \\
\hline EEA & $20-30$ & $5-10$ & $30-40$ & $10-20$ & $10-20$ & $10-20$ \\
\hline UK**** & 8 & 6 & - & 30 & 38 & 5 \\
\hline
\end{tabular}

*As reported in EEA merger report[25], estimates of market shares are submitted by the parties

**Figures are reported as percentage ranges for confidentiality reasons

***Suppliers which only appear in 2 or less of the countries in the report, have been removed from the table

$* * * *$ UK figure is taken from table 1 